\title{
Multiple Resistance of Botrytis cinerea from Vegetable Crops to Carbendazim, Diethofencarb, Procymidone, and Pyrimethanil in China
}

\author{
Hai-Yan Sun, Han-Cheng Wang, Yu Chen, Hong-Xia Li, Chang-Jun Chen, and Ming-Guo Zhou, College of \\ Plant Protection, Nanjing Agricultural University, Nanjing 210095, P. R. China
}

\begin{abstract}
Sun, H.-Y., Wang, H.-C., Chen, Y., Li, H.-X., Chen, C.-J., and Zhou, M.-G. 2010. Multiple resistance of Botrytis cinerea from vegetable crops to carbendazim, diethofencarb, procymidone, and pyrimethanil in China. Plant Dis. 94:551-556.

One hundred and eight isolates of Botrytis cinerea from greenhouse cucumber and tomato in two locations in Jiangsu Province (Nanjing and Huaiyin) and one location in Shandong Province were tested for their sensitivities to the four fungicides commonly used in China. Isolates with resistance to all four fungicides - carbendazim, diethofencarb, procymidone, and pyrimethanil $\left(\mathrm{Car}^{\mathrm{R}} \operatorname{Die}^{\mathrm{R}} \operatorname{Prc}^{\mathrm{R}} \mathrm{Pyr}^{\mathrm{R}}\right)$ - were found in all three regions in this study. High frequencies (52 and $53 \%$ ) of resistance to all four fungicides were observed among the 62 isolates collected in Nanjing and the 36 isolates collected in Huaiyin in Jiangsu Province. The 10 isolates from Shandong Province were all resistant to the four fungicides. Pathogenicity and sporulation in vivo, and mycelial growth, sporulation, spore germination, and osmotic sensitivity to $\mathrm{NaCl}$ in vitro, were similar for the group of quadruple-resistant and wild-type isolates $(P>0.05)$. In the present study, the complete two-component histidine kinase gene (Bos1) was sequenced for 10 procymidone-resistant and 3 procymidone-sensitive $B$. cinerea isolates. Isolates representing four different procymidone-resistant phenotypes $\left(\mathrm{Car}^{\mathrm{R}} \operatorname{Die}^{\mathrm{S}} \operatorname{Prc}^{\mathrm{R}} \mathrm{Pyr}^{\mathrm{S}}, \quad \mathrm{Car}^{\mathrm{R}} \operatorname{Die}^{\mathrm{R}} \operatorname{Prc}^{\mathrm{R}} \mathrm{Pyr}^{\mathrm{S}}, \quad \mathrm{Car}^{\mathrm{R}} \mathrm{Die}^{\mathrm{R}}\right.$ $\operatorname{Prc}^{\mathrm{R}} \operatorname{Pyr}^{\mathrm{R}}$, and $\left.\mathrm{Car}^{\mathrm{R}} \operatorname{Die}^{\mathrm{R}} \operatorname{Prc}^{\mathrm{R}} \operatorname{Pyr}^{\mathrm{R}}\right)$ all had nucleic acid point mutations resulting in amino acid changes at position 369 (change from glutamine to proline) as well as at amino acid position 373 (asparagine to serine) in the Bosl gene.
\end{abstract}

Gray mold, caused by Botrytis cinerea Pers. (teleomorph: Botryotinia fuckeliana), is a common disease that causes severe economic losses of greenhouse vegetable crops such as tomato, cucumber, and eggplant. Control of gray mold worldwide has largely depended on several classes of synthetic fungicides with different modes of action. Fungicide resistance, however, frequently develops in this pathogen. To reduce the development of fungicide resistance in $B$. cinerea, growers trying to control gray mold on vegetable crops in China have applied mixtures of fungicides or have alternated fungicides $(5,10,27)$, especially in Shangdong and Jiangsu Province. These fungicides include benzimidazoles, particularly carbendazim; the mixture of benzimidazoles and $N$-phenylcarbamates, such as the mixture of carbendazim and diethofencarb; dicarboximides, such as procymidone; and the anilinopyrimidine fungicide pyrimethanil.

Corresponding author: M.-G. Zhou

E-mail:mgzhou@njau.edu.cn

and yumucun@126.com

H.-Y. Sun, H.-C. Wang, and Y. Chen share joint first authorship.

Accepted for publication 29 November 2009.

doi:10.1094/PDIS-94-5-0551

(C) 2010 The American Phytopathological Society
Benzimidazoles (carbendazim and thiophanate-methyl) have been and are still widely used against gray mold in China but resistance to benzimidazoles in $B$. cinerea often results in the failure of gray mold control $(5,27) . \mathrm{N}$-phenylcarbamates often exhibit negative cross resistance with benzimidazole fungicides, so that benzamidazole-sensitive wild-type $B$. cinerea isolates generally are resistant to $N$ phenylcarbamates (diethofencarb) while benzimidazole-resistant $B$. cinerea generally are sensitive to $N$-phenylcarbamates $(11,13)$. Therefore, a mixture of carbendazim and diethofencarb (Jonk; Sumitomo Chemical Company, Osaka, Japan), was released to control gray mold (11). Because of intensive use of the mixture, however, isolates showing dual resistance to benzimidazoles and $N$-phenylcarbamates were commonly detected in many countries soon after the mixture became commercially available $(7,11)$. Their antifungal effect results from inhibition of microtubule assembly which is due to their binding to $\beta$-tubulin, the main microtubule structural protein. Resistance to this class of fungicides has been reported many times and is related to point mutations in the $\beta$-tubulin gene $(13,25)$.

Dicarboximides (procymidone and iprodione) replaced the benzimidazoles in the late 1970s and have been used for control of gray mold for more than two decades (27). However, the spread of dicar- boximide-resistant $B$. cinerea has greatly reduced the efficacy of dicarboximides in many countries $(6,16,21)$. Point mutations in the two-component histidine kinase gene $(B o s 1)$ were confirmed to be associated with dicarboximide resistance in the field $(15,20)$. Seven types of point mutations of the Bosl gene were identified in dicarboximide-resistant populations of $B$. cinerea from different host plants from different countries $(15,20)$ : single amino acid substitutions within Bosl gene, (i) ${ }^{365}$ Ile to Asn, (ii) ${ }^{365}$ Ile to Arg, or (iii) ${ }^{365}$ Ile to Ser; two amino acid substitutions within Bosl gene, (iv) ${ }^{365}$ Ile to Ser and ${ }^{369}$ Glu to Pro, (v) ${ }^{369}$ Gln to Pro and ${ }^{373}$ Asn to Ser; three amino acid substitutions within Bos1 gene, (vi) ${ }^{368}$ Val to Phe, ${ }^{369} \mathrm{Gln}$ to His, and ${ }^{447} \mathrm{Thr}$ to Ser; and (vii) a substitution of CGA for TGA at the amino acid position 1040, which is predicted to introduce a stop codon at this position. Moreover, previous studies also reported that high levels of dicarboximide resistance could be induced in the laboratory. These laboratory-induced dicarboximide-resistant isolates exhibited greater osmotic sensitivity in several fungi with decreased aggressiveness, whereas field isolates with dicarboximide resistance did not exhibit changed osmotic sensitivity and remained highly aggressive on plants (15), suggesting that the field-resistant isolates might have sufficient parasitic fitness to compete with field-sensitive isolates. Although the dicarboximides have been used for many years, the resistance mechanism in isolates of $B$. cinerea from vegetable crops grown in China was unknown.

In recent years, anilinopyrimidine fungicides (such as pyrimethanil and cyprodinil) were registered for control of gray mold on vegetable crops worldwide (13). This group of fungicides is effective in controlling gray mold and effective against benzimidazole- and dicarboximideresistant populations in the field (13). Pyrimethanil was registered in 1998 for control gray mold on vegetable crops in China (10). Antifungal activity in vitro may result from a block in the excretion of hydrolytic enzymes involved in the pathogenic processes or the inhibition of methionine biosynthesis (12). Numerous reports of the occurrence of field isolates of $B$. cinerea resistant to anilinopyrimidines were made several years after its registration for commercial use $(1,2,8,10,12,13$, 17,18). Moreover, the occurrence of the 
field $B$. cinerea isolates resistant to all the $\mathrm{N}$-phenylcarbamates, dicarboximides, and anilinopyrimidine ) was recently reported in Spain (17).

Growers have often complained that the recommended fungicides in all four classes are ineffective in controlling gray mold on vegetables in Shandong and Jiangsu Province (unpublished data), which might be caused by the resistance of $B$. cinerea to these fungicides.

In order to understand why these fungicides fail to control gray mold, the objectives of the current study were to (i) test the sensitivity of $108 \mathrm{~B}$. cinerea isolates collected from Shandong and Jiangsu Province to the four fungicides carbendazim, diethofencarb, procymidone, and pyrimethanil; (ii) identify fungicideresistant isolates; (iii) compare several fitness components of these fungicideresistant or -sensitive isolates; and (iv) analyze the Bosl gene for mutations associated with field resistance to dicarboximides. Presumably, information on the current resistance status of $B$. cinerea populations can be used to develop strategies to manage resistance and avoid unexpected control failures.

\section{MATERIALS AND METHODS}

Isolates and fungicides. Diseased fruit or leaves of tomato (Lycopersicon esculentum Mill.) or cucumber (Cucumis sativus Linn) with obvious spores were collected from various greenhouses in Nanjing, and Huaiyin (Jiangsu Province) in 2008 and in Shouguang (Shandong Province) in 2007, where the four fungicide classes (benzimidazoles, dicarboximides, a mixture of $\mathrm{N}$ phenylcarbamates and benzimidazoles, and anilinopyrimidines) with different modes of action were used every 10 to 15 days on duction system from 1992 to 2006. Different greenhouses in the same province were at least $10 \mathrm{~km}$ apart. Greenhouses in different provinces were at least $200 \mathrm{~km}$ four classes of fungicides (benzimidazoles, crops in the continuous greenhouse pro-

apart. The mixture of conidiophores and conidia was suspended in water, transferred onto $2 \%$ water agar in dishes, and incubated at $22^{\circ} \mathrm{C}$ for $6 \mathrm{~h}$. Pieces of agar containing only one spore were removed from the water agar using a dissecting scope and placed onto potato dextrose agar (PDA; $200 \mathrm{~g}$ of potato, $20 \mathrm{~g}$ of dextrose, $16 \mathrm{~g}$ of agar, and 1 liter of $\mathrm{H}_{2} \mathrm{O}$ ) plates amended with streptomycin at $0.5 \mathrm{~g} \mathrm{liter}^{-1}$ to minimize contamination with bacteria. Mycelium from pure cultures was transferred to PDA slants and stored at $4^{\circ} \mathrm{C}$ in the dark. In 2008, 62 isolates were collected from tomato plants in seven greenhouses and cucumber plants in six greenhouses in Nanjing; 36 isolates were collected from eight tomato and five cucumber greenhouses in Huaiyin; and, in 2007, 10 isolates were collected from five tomato and five cucumber greenhouses in Shouguang (Table 1). Additionally, another five single-spore isolates (YC4, YC5, $\mathrm{YC} 15, \mathrm{Y} 71$, and $\mathrm{X} 9$ ), which were stored in our laboratory, were used in this experiment as fungicide-sensitive controls for comparison with quadruple-resistant isolates. Three of them (YC4, YC5, and YC15) were collected from Yancheng in Jiangsu province in 2007 and two singlespore isolates (Y71 and X9) were collected from Yancheng in 2004. These five isolates (YC4, YC5, YC15, Y71, and X9) were all confirmed to be sensitive to carbendazim, procymidone, and pyrimethanil but resistant to diethofencarb (as expected for benzimidazole-sensitive isolates) based on previous studies (unpublished data). These isolates were considered to be the wildtype isolates (11) and used as comparisons for fungicide assays as described below.

Technical-grade procymidone $(98 \%$ active ingredient [a.i.]; Sumitomo Chemical Company), diethofencarb (90\% a.i.; Jiangsu Suzhou Chemical Group Xinyi Agrochemical Co., Ltd., Jiangsu, China), and pyrimethanil $\quad(95.0 \%$ a.i.; Fengdeng Chemical Factory, Jiangsu, China) were each dissolved in methanol to obtain stock

Table 1. Frequency of fungicide-resistant phenotypes of Botrytis cinerea isolates collected from greenhouses in Jiangsu Province in 2008 and in Shandong Province in 2007

\begin{tabular}{|c|c|c|c|}
\hline \multirow[b]{3}{*}{ Phenotype $^{\text {b }}$} & \multicolumn{3}{|c|}{ Occurrence of phenotype $(\%)^{a}$} \\
\hline & \multicolumn{2}{|c|}{ Jiangsu Province } & \multirow{2}{*}{$\begin{array}{c}\text { Shandong Province } \\
\text { Shouguang (10) }\end{array}$} \\
\hline & Nanjing $(62)^{b}$ & Huaiyin (36) & \\
\hline $\mathrm{Car}^{\mathrm{R}}$ & 100 & 100 & 100 \\
\hline $\mathrm{Die}^{\mathrm{R}}$ & 88.5 & 75.0 & 100 \\
\hline $\operatorname{Prc}^{\mathrm{R}}$ & 98.4 & 86.1 & 100 \\
\hline $\mathrm{Pyr}^{\mathrm{R}}$ & 53.2 & 61.1 & 100 \\
\hline $\mathrm{Car}^{\mathrm{R}} \mathrm{Die}^{\mathrm{S}} \mathrm{Prc}^{\mathrm{S}} \mathrm{Pyr}^{\mathrm{S}}$ & 0.0 & 8.3 & 0 \\
\hline $\mathrm{Car}^{\mathrm{R}} \mathrm{Die}^{\mathrm{R}} \mathrm{Prc}^{\mathrm{S}} \mathrm{Pyr}^{\mathrm{S}}$ & 0 & 5.6 & 0 \\
\hline $\mathrm{Car}^{\mathrm{R}} \mathrm{Die}^{\mathrm{S}} \mathrm{Prc}^{\mathrm{R}} \mathrm{Pyr}^{\mathrm{S}}$ & 9.8 & 8.3 & 0 \\
\hline $\operatorname{Car}^{R} \operatorname{Die}^{S} \operatorname{Prc}^{S} \mathrm{Pyr}^{\mathrm{R}}$ & 1.6 & 5.6 & 0 \\
\hline $\mathrm{Car}^{\mathrm{R}} \mathrm{Die}^{\mathrm{R}} \operatorname{Prc}^{\mathrm{R}} \mathrm{Pyr}^{\mathrm{S}}$ & 37.1 & 22.2 & 0 \\
\hline $\operatorname{Car}^{R} \operatorname{Die}^{S} \operatorname{Prc}^{R} \operatorname{Pyr}^{R}$ & 0 & 2.8 & 0 \\
\hline $\operatorname{Car}^{\mathrm{R}} \operatorname{Die}^{\mathrm{R}} \operatorname{Prc}^{\mathrm{R}} \operatorname{Pyr}^{\mathrm{R}}$ & 51.6 & 52.8 & 100 \\
\hline
\end{tabular}

${ }^{a}$ Regions of collection; numbers of isolates tested are given in parentheses.

${ }^{\mathrm{b}}$ Car, carbendazim; Die, diethofencarb; Prc, procymidone; Pyr, pyrimethanil; superscripts $\mathrm{R}$ and $\mathrm{S}$ indicate resistant and sensitive, respectively. solutions of $10 \mathrm{mg} / \mathrm{ml}$. Technical-grade carbendazim (98\% a.i.; Zhenjiang Chemical Factory, Zhenjiang, China) was dissolved in $0.1 \mathrm{M} \mathrm{HCl}$ to obtain a $10 \mathrm{mg} / \mathrm{ml}$ stock solution. All fungicide stock solutions were stored at $4^{\circ} \mathrm{C}$ in the dark to preserve fungicide activity and were added to autoclaved media when the media had cooled to approximately $50^{\circ} \mathrm{C}$. The volumes of methanol and $\mathrm{HCl}$ solutions were less than $0.25 \%$ of the fungicide solutions and these concentrations did not affect mycelial growth of $B$. cinerea (data not shown). The controls always contained the same methanol or $\mathrm{HCl}$ concentration as the test samples in the experiments.

Determination of the fungicide sensitivity of $B$. cinerea isolates. Single discriminatory concentration testing was used in this study $(2,17)$. To assess sensitivity to carbendazim, procymidone, and diethofencarb, mycelial growth of the isolates was measured on PDA amended with a discriminatory dose of carbendazim at 1 $\mathrm{mg} / \mathrm{liter}$, procymidone at $5 \mathrm{mg} / \mathrm{liter}$, or diethofencarb at $5 \mathrm{mg} / \mathrm{liter}$ (17). A 5-mmdiameter agar plug was cut with a cork borer from the edge of 3-day-old colony growing on PDA at $25^{\circ} \mathrm{C}$ and was placed upside-down on the center of each plate containing fungicide-amended medium To assess pyrimethanil resistance in $B$. cinerea, 17 h-old germinated conidia were prepared (9) as follows. L-asparaginebased agar medium (ASP-agar) was amended with pyrimethanil at $1 \mathrm{mg} / \mathrm{liter}$ (9). Cultures of the isolates were incubated in the dark for 5 days at $25^{\circ} \mathrm{C}$ and then for an additional 7 days under fluorescent light at $22^{\circ} \mathrm{C}$. Each plate was flooded with $5 \mathrm{ml}$ of sterile water and gently scraped to suspend the conidia. The conidial suspensions were filtered with two layers of gauze and the suspension was adjusted to approximately $1 \times 10^{5}$ conidia/ml. An aliquot (200 $\mu \mathrm{l})$ of the conidial suspension was then spread onto $1.6 \%$ fungicide-free water agar plates and incubated at $23^{\circ} \mathrm{C}$. After $17 \mathrm{~h}$, a 5 -mm-diameter plug was cut from each water agar plate and placed upside-down on the center of a new plate containing ASP-agar with or without pyrimethanil.

The radial growth of each isolate was measured after 3 days at $25^{\circ} \mathrm{C}$ in the dark. For each isolate and fungicide, three replicates with and without fungicide were used and the experiment was conducted twice. For carbendazim, procymidone, diethofencarb, and pyrimethanil, isolates were designated resistant if they grew on the unamended agar (control) and on the fungicide-amended agar, and they were designated sensitive if they showed no growth on the fungicide-amended agar.

Selection of isolates and sensitivity determination. After fungicide resistance was assessed, 5 wild-type isolates (sensitive to carbendazim, procymidone, and pyrimethanil but resistant to diethofencarb) and 10 isolates resistant to all four fungi- 
cides were arbitrarily selected to characterize response to a range of fungicide doses (Table 2). Sensitivity of the selected isolates to different concentrations of carbendazim, diethofencarb, and procymidone was determined using the mycelial growth assay and the sensitivity to different concentrations of pyrimethanil was determined using the assay with 17-h-old germinated spores, as described above. Mean colony diameter (minus the diameter of inoculation plug) was measured after 3 days of incubation for each treatment by calculating the mean of two perpendicular colony diameters and expressed as percentage of growth inhibition $=1-($ mean colony diameter on amended media/mean colony diameter on nonamended media) $x$ 100. The median effective concentration $\left(\mathrm{EC}_{50}\right)$ values for each isolate were calculated by regressing percent growth inhibition against the log of fungicide concentration as described previously (12). Three replicates per concentration were used and all the tests were conducted twice.

Mycelial growth, spore production, and conidia germination of wild-type and quadruple-resistant isolates in vitro. Mycelial growth in vitro of each of the 15 isolates tested above was measured on fungicide-free PDA plates, with five replicates. The colony diameter was measured after the fungi had been incubated at $23^{\circ} \mathrm{C}$ for 4 days in darkness to assess radial growth. To measure conidial production and germination frequency, the plates were then incubated for an additional 7 days under fluorescent light at room temperature. Conidia from each isolate were collected as described earlier, with a final volume of $5 \mathrm{ml}$ for each conidial suspension in sterile water, and the conidial concentration in the suspension was measured with a hemacytometer. After the number of conidia produced by each isolate was determined, 100- $\mu$ l aliquots of each conidial suspension were spread onto $2 \%$ water agar. After $12 \mathrm{~h}$ at $23^{\circ} \mathrm{C}$, the percentage of conidia that germinated was determined by examining 100 conidia at each of three sites in the petri dish with the help of a microscope. Three replicate plates were examined for each isolate. Conidia with a germ tube length at least twice the length of the conidium were considered germinated. All these tests on mycelial growth, spore production, and conidia germination were conducted twice.

Aggressiveness and production of conidia by both wild-type and quadrupleresistant $B$. cinerea isolates in vivo. $\mathrm{Cu}$ cumber plants ( $C$. sativa L. cv. Xintaimici) were grown in pots in the greenhouse at $25^{\circ} \mathrm{C}$. To determine the aggressiveness of the $15 \mathrm{~B}$. cinerea isolates, the cotyledon of a 3-week-old cucumber seedling was removed from the plant and inoculated with a 5-mm mycelial plug taken from the edge of a 3-day-old PDA colony of each isolate. Five replicate cotyledons per isolate were inoculated and then placed on a filter paper in a $20-\mathrm{cm}$-diameter glass petri dish. Water $(5 \mathrm{ml})$ was added to the filter paper to maintain high relative humidity and the dish was covered with its lid. The petri dishes were incubated in a growth chamber ( $16 \mathrm{~h}$ of daylight, $22^{\circ} \mathrm{C}$ ). After 5 days, the mean diameter of the infected cucumber tissue was measured. Meanwhile, the number of conidia produced on each cotyledon was quantified according to a previously described method (1). The tissue segments (about $20 \mathrm{~mm}^{2}$ ) with sporulating lesions were removed from the cotyledons with the aid of a cork borer (5-mmdiameter). Each cotyledon was sampled once. Then, all the cotyledon segments for each isolate were placed in an Eppendorf tube with $3 \mathrm{ml}$ of distilled water and were vigorously mixed with a vortex mixer to wash the conidia from the lesions. After the cotyledon segments were removed, a droplet of the conidial suspension was placed in a hemacytometer and the number of conidia was counted. Four replicate droplets were counted for each tube. Conidia production was expressed as the number of conidia per square millimeter of diseased cotyledon surface. These two tests on aggressiveness and production of conidia were conducted twice.

Osmotic sensitivity. To test the osmotic sensitivity of the 5 wild-type and 10 quadruple-resistant isolates of $B$. cinerea, a 5mm-diameter mycelial plug from the edge of a 3-day-old PDA culture was transferred to the center of a PDA plate amended with a series of $\mathrm{NaCl}$ concentrations; the concentrations of $\mathrm{NaCl}$ in the medium were 0 , $1,2,4,6$, and $8 \%$ (wt/vol). After 4 days at $25^{\circ} \mathrm{C}$ in the dark, the colony diameters were measured. The inhibition of the mycelial radial growth by $\mathrm{NaCl}$ was expressed as a percentage of the growth in medium lacking $\mathrm{NaCl}$. This experiment was conducted twice with three replicates.

Sequences of the Bos 1 gene from procymidone-resistant and -sensitive isolates. In the present study, procymidoneresistant isolates with different phenotypes were detected from 108 isolates. Isolates with one of the following five phenotypes (superscript $\mathrm{R}$ indicates resistance and superscript $\mathrm{S}$ indicates sensitivity) were arbitrarily selected: $\mathrm{Car}^{\mathrm{S}} \mathrm{Die}^{\mathrm{R}} \mathrm{Prc}^{\mathrm{S}} \mathrm{Pyr}^{\mathrm{S}}$ (isolates YC4, YC5, and YC15), Car ${ }^{\mathrm{R}}$ $\mathrm{Die}^{\mathrm{S}} \mathrm{Prc}^{\mathrm{R}} \mathrm{Pyr}^{\mathrm{S}}$ (isolates 08-NJ57, 08-HY8, and 08-HY15), $\mathrm{Car}^{\mathrm{R}} \mathrm{Die}^{\mathrm{R}} \operatorname{Prc}^{\mathrm{R}} \mathrm{Pyr}^{\mathrm{S}}$ (isolates 08-NJ37, 08-NJ16, and 08-NJ29), Car ${ }^{\mathrm{R}}$

Table 2. Fungicide concentrations used to determine the median effective concentration value for sensitive and resistant isolates of Botrytis cinerea

\begin{tabular}{lll}
\hline & \multicolumn{2}{c}{ Concentrations (mg/liter) for } \\
\cline { 2 - 3 } Fungicides & \multicolumn{1}{c}{ Sensitive isolates } & \multicolumn{1}{c}{ Resistant isolates } \\
\hline Carbendazim & $0.016,0.031,0.063,0.125,0.25$ & $1,5,10,20,30,40,50$ \\
Diethofencarb & $0.016,0.031,0.063,0.125,0.25$ & $5,10,20,30,40,50$ \\
Procymidone & $0.031,0.063,0.125,0.25,0.5,1$ & $0.5,1,2,4,8,16$ \\
Pyrimethanil & $0.031,0.063,0.125,0.25,0.5,1$ & $3.125,6.25,12.5,25,50,100$ \\
\hline
\end{tabular}

$\mathrm{Die}^{\mathrm{S}} \operatorname{Prc}^{\mathrm{R}} \mathrm{Pyr}^{\mathrm{R}}$ (isolate 08-HY32), and $\mathrm{Car}^{\mathrm{R}}$ $\mathrm{Die}^{\mathrm{R}} \mathrm{Prc}^{\mathrm{R}} \mathrm{Pyr}^{\mathrm{R}}$ (isolates 08-NJ45, 08-NJ54, and 08-NJ59). To extract fungal genomic DNA, 10 mycelial plugs from each of the 13 isolates were cut from the edge of 3day-old culture on PDA and placed in a $200-\mathrm{ml}$ flask containing $100 \mathrm{ml}$ of potato dextrose broth $(200 \mathrm{~g}$ of potato and $20 \mathrm{~g}$ of dextrose per liter of water). After 3 days at $25^{\circ} \mathrm{C}$ in darkness, mycelia of each isolate were harvested, washed three times with sterile water, and freeze dried. Genomic DNA was extracted according to the method described before (28) with modifications. Briefly, the mycelia were ground with a mortar and pestle using quartz sand (Sinopharm Chemical Reagent Co., Ltd., Shanghai, China) with liquid nitrogen. The powder was suspended in extraction buffer containing $10 \mathrm{mM}$ Tris- $\mathrm{HCl}(\mathrm{pH} 7.5), 50$ captoethanol and heated at $65^{\circ} \mathrm{C}$ for 30 min. The suspensions were centrifuged at $13,000 \mathrm{rpm}$ for $5 \mathrm{~min}$, and the supernatants collected, treated with $10 \mu \mathrm{g}$ of RNase, incubated at $37^{\circ} \mathrm{C}$ for $1 \mathrm{~h}$, and subsequently extracted three times with phenolchloroform-isoamyl alcohol (25:24:1). The aqueous layers were extracted with chloroform-isoamyl alcohol (24:1) twice and isopropyl alcohol was added to form the precipitate of DNA. The pellet of DNA was collected by centrifugation, washed with $70 \%$ cold ethanol, and resuspended in Tris-EDTA (TE) buffer containing $10 \mathrm{mM}$ Tris- $\mathrm{HCl}$ and $1 \mathrm{mM}$ EDTA, $\mathrm{pH}$ 8.0, after drying, and stored at $-20^{\circ} \mathrm{C}$. All primers were synthesized by Shanghai Sangon Biological Engineering Technology and Service Co., Ltd. (China). Five pairs of PCR primers described by Ma et al. (15) were used to amplify the Bos 1 gene (GenBank accession number AF396827) for all the isolates, based on the previously reported DNA sequence of the Bosl gene. All amplified PCR products were purified by electrophoresis, cloned into the pMD19-T Vector (TaKaRa Biotechnology Co., Ltd. Dalian, China) according to the manufacturers' instructions, and sequenced by Shanghai Sangon Biological Engineering Technology and Service Co., Ltd. in both directions. Sequence differences between procymidone-sensitive and -resistant isolates were analyzed with programs in the BioEdit software (4).

Statistical analysis. All statistical analyses were conducted using SPSS 14.0 (SPSS Inc., Chicago). Analysis of variance mM EDTA, $100 \mathrm{mM} \mathrm{LiCl}$, and $0.2 \%$ mer- 
between the two repeated experiments and differences in fitness components between the quadruple-resistant group and wildtype group of isolates were compared by $t$ tests.

Fungicide resistance of the $B$. cinerea isolates. In total, 108 isolates of $B$. cinerea collected from Jiangsu Province and Shandong Province were tested for resistance to carbendazim, diethofencarb, procymidone, and pyrimethanil. The 10 isolates from Shandong Province were resistant to all four fungicides (Table 1). Isolates resistant to at least one of the fungicides were also

\section{RESULTS}

very common in Jiangsu Province and $100 \%$ of the isolates were carbendazim resistant, more than $75 \%$ were diethofencarb resistant, and more than $86 \%$ were procymidone resistant (Table 1). A smaller percentage of the isolates were resistant to pyrimethanil than to the other fungicides. Also, in Jiangsu Province, most of the $B$. cinerea isolates had multiple resistances to the fungicides and about half of the isolates were resistant to all the four fungicides tested (Table 1). Seven phenotypes $\left(\mathrm{Car}^{\mathrm{R}} \mathrm{Die}^{\mathrm{S}} \mathrm{Prc}^{\mathrm{S}} \mathrm{Pyr}^{\mathrm{S}}, \quad \mathrm{Car}^{\mathrm{R}} \mathrm{Die}^{\mathrm{R}} \mathrm{Prc}^{\mathrm{S}} \mathrm{Pyr}^{\mathrm{S}}\right.$, Car ${ }^{\mathrm{R}} \operatorname{Die}^{\mathrm{S}} \operatorname{Prc}^{\mathrm{R}} \mathrm{Pyr}^{\mathrm{S}}, \quad \operatorname{Car}^{\mathrm{R}} \operatorname{Die}^{\mathrm{S}} \operatorname{Prc}^{\mathrm{S}} \mathrm{Pyr}^{\mathrm{R}}$, Car ${ }^{R} \operatorname{Die}^{\mathrm{R}} \operatorname{Prc}^{\mathrm{R}} \mathrm{Pyr}^{\mathrm{s}}, \quad \mathrm{Car}^{\mathrm{R}} \mathrm{Die}^{\mathrm{S}} \operatorname{Prc}^{\mathrm{R}} \mathrm{Pyr}^{\mathrm{R}}$, $\mathrm{Car}^{\mathrm{R}} \operatorname{Die}^{\mathrm{R}} \operatorname{Prc}^{\mathrm{R}} \operatorname{Pyr}^{\mathrm{R}}$ ) were detected from

Table 3. Sensitivity of wild-type isolates of Botrytis cinerea and isolates resistant to carbendazim, procymidone, diethofencarb, and pyrimethanil

\begin{tabular}{|c|c|c|c|c|}
\hline & \multicolumn{4}{|c|}{$\mathbf{E C}_{50}(\mathrm{mg} / \text { liter })^{\mathrm{a}}$} \\
\hline & Carbendazim & Diethofencarb & Procymidone & Pyrimethanil \\
\hline \multicolumn{5}{|c|}{ Wild-type isolates } \\
\hline $\mathrm{YC} 4$ & 0.14 & $>50$ & 0.15 & 0.05 \\
\hline YC5 & 0.11 & $>50$ & 0.38 & 0.06 \\
\hline YC15 & 0.15 & $>50$ & 0.22 & 0.13 \\
\hline Y71 & 0.07 & $>50$ & 0.20 & 0.09 \\
\hline X9 & 0.15 & $>50$ & 0.27 & 0.08 \\
\hline \multicolumn{5}{|c|}{ Resistant isolates } \\
\hline 07-SD3 & $>50$ & $>50$ & 2.54 & 25.13 \\
\hline 08-NJ54 & $>50$ & $>50$ & 3.64 & 14.79 \\
\hline 08-NJ59 & $>50$ & $>50$ & 1.82 & 13.25 \\
\hline 07-SD5 & $>50$ & $>50$ & 2.06 & 23.72 \\
\hline $08-\mathrm{NJ} 26$ & $>50$ & 44.75 & 2.63 & 24.61 \\
\hline $08-\mathrm{NJ} 23$ & $>50$ & $>50$ & 4.02 & 24.38 \\
\hline 08-NJ30 & $>50$ & $>50$ & 1.72 & 22.34 \\
\hline 08-NJ5 & $>50$ & $>50$ & 2.43 & 23.83 \\
\hline 08-NJ6 & $>50$ & $>50$ & 2.08 & 14.16 \\
\hline 08-HY3 & $>50$ & $>50$ & 2.4 & 27.05 \\
\hline
\end{tabular}

108 isolates (Table 1). Other possible resistance phenotypes were not detected.

Sensitivity of selected isolates to carbendazim, diethofencarb, procymidone, and pyrimethanil. In the in vitro sensitivity test, the $\mathrm{EC}_{50}$ values of the five wildtype isolates of $B$. cinerea ranged from 0.07 to $0.15 \mathrm{mg} / \mathrm{liter}$ to carbendazim (Table 3). In contrast, the 10 quadrupleresistant isolates were highly resistant to carbendazim; the $\mathrm{EC}_{50}$ values for these isolates exceeded $50 \mathrm{mg} /$ liter (Table 3 ). The wild-type isolates and the quadrupleresistant isolates were highly resistant to diethofencarb, with $\mathrm{EC}_{50}$ values more than $50 \mathrm{mg} / \mathrm{liter}$, except the isolate 08$\mathrm{NJ} 26$, with an $\mathrm{EC}_{50}$ value of 44.75 $\mathrm{mg} /$ liter (Table 3). For procymidone, the $\mathrm{EC}_{50}$ values of the 5 wild-type isolates ranged from 0.15 to $0.38 \mathrm{mg} /$ liter and those of the 10 quadruple-resistant isolates ranged from 1.72 to $4.02 \mathrm{mg} / \mathrm{liter}$ (Table 3); the resistant isolates had low or moderate resistance to procymidone and were about 10 times more resistant than the sensitive isolates. The $\mathrm{EC}_{50}$ values of the wild-type and the quadruple-resistant isolates for pyrimethanil were 0.05 to 0.13 and 13.25 to $27.05 \mathrm{mg} / \mathrm{liter}$, respectively (Table 3).

Growth, sporulation, spore germination, aggressiveness, and sensitivity to $\mathrm{NaCl}$ in wild-type and quadrupleresistant isolates. The mean mycelial diameters of groups of wild-type and quadruple-resistant isolates on unamended media were $6.48 \pm 1.06$ and $6.09 \pm 0.73 \mathrm{~mm}$, and there was no significant difference between the two groups in mycelial growth $(P>0.05)$. Within the group of quadrupleresistant isolates, 08-NJ30 grew significantly more slowly than the other isolates (Table 4). Mean spore production in vitro

Table 4. Fitness components wild-type isolates of Botrytis cinerea and isolates resistant to carbendazim, procymidone, diethofencarb, and pyrimethanil

\begin{tabular}{|c|c|c|c|c|c|}
\hline \multirow[b]{3}{*}{ Isolates } & \multicolumn{5}{|c|}{ Fitness components $^{\mathrm{a}}$} \\
\hline & \multicolumn{3}{|c|}{ In vitro experiments } & \multicolumn{2}{|c|}{ In vivo experiments } \\
\hline & $\begin{array}{l}\text { Mycelial growth } \\
(\mathrm{cm})\end{array}$ & $\begin{array}{c}\text { Sporulation } \\
\left(\times 10^{6} \mathrm{ml}^{-1}\right)\end{array}$ & $\begin{array}{c}\text { Spore germination } \\
(\%)\end{array}$ & $\begin{array}{l}\text { Lesion size } \\
(\mathrm{cm})\end{array}$ & $\begin{array}{c}\text { Sporulation (conidia } \times \\
10^{5} / \mathrm{cm}^{2} \text { of leaf) }\end{array}$ \\
\hline \multicolumn{6}{|c|}{ Wild-type isolates } \\
\hline $\mathrm{YC} 4$ & 7.4 & 3.7 & 96.9 & 4.3 & 8.0 \\
\hline YC5 & 6.4 & 6.1 & 92.7 & 3.8 & 3.8 \\
\hline YC15 & 7.7 & 4.2 & 89.4 & 4.4 & 2.7 \\
\hline Y71 & 5.3 & 0.5 & 88.2 & 3.2 & 0.9 \\
\hline X9 & 5.6 & 0.6 & 92.0 & 3.8 & 3.1 \\
\hline \multicolumn{6}{|c|}{ Resistant isolates } \\
\hline 07-SD3 & 6.4 & 4.3 & 94.5 & 3.6 & 5.7 \\
\hline 08-NJ54 & 6.8 & 4.0 & 84.0 & 3.9 & 6.4 \\
\hline 08-NJ59 & 5.5 & 3.2 & 87.4 & 3.4 & 2.4 \\
\hline 07-SD5 & 6.1 & 0.8 & 96.5 & 4.0 & 0.9 \\
\hline $08-\mathrm{NJ} 26$ & 6.5 & 6.2 & 93.4 & 3.9 & 3.1 \\
\hline $08-\mathrm{NJ} 23$ & 7.3 & 0.5 & 96.2 & 4.2 & 0.5 \\
\hline $08-\mathrm{NJ} 30$ & 4.9 & 6.2 & 94.5 & 2.7 & 4.8 \\
\hline 08-NJ5 & 6.3 & 3.0 & 93.0 & 4.0 & 3.6 \\
\hline 08-NJ6 & 5.3 & 12.1 & 99.0 & 3.8 & 18.7 \\
\hline 08-HY3 & 5.8 & 8.1 & 96.7 & 3.9 & 11.5 \\
\hline
\end{tabular}

a Values are the mean of two experiments with three replicates each. Analysis of variance did not show significant differences $(P>0.05)$ between the two experiments according to the $t$ test. Resistant isolates were resistant to all four fungicides. Mycelial growth, spore production, spore germination percentage in vitro and spore production and lesion size in vivo did not differ significantly $(P>0.05)$ between the group of resistant and wild-type isolates according to $t$ tests. 
for the group of wild-type isolates had a value of $(3.02 \pm 2.43) \times 10^{6}$ spores $/ \mathrm{ml}$, which was similar $(P>0.05)$ to the mean spore production in vitro of the quadrupleresistant isolates with mean values of $(4.84$ $\pm 4.38) \times 10^{6}$ spores $/ \mathrm{ml}$ (Table 4). The groups of both wild-type and quadrupleresistant isolates had similar $(P>0.05)$ conidia germination percentages of $91.8 \pm$ 3.38 and $93.5 \pm 4.55 \%$, respectively, in vitro (Table 4). In the pathogenicity test, none of the quadruple-resistant isolates of $B$. cinerea lost their ability to infect cucumber cotyledons, and most of them were as aggressive as the wild-type isolates $(P>$ 0.05 ) (Table 4). The quadruple-resistant isolates, as a group, produced mean number of $(3.70 \pm 2.63) \times 10^{5}$ conidia $/ \mathrm{cm}^{2}$ of leaf on diseased cucumber tissues, a number which was not significantly different $(P>0.05)$ from the mean number of $(5.76$ $\pm 5.54) \times 10^{5}$ conidia $/ \mathrm{cm}^{2}$ of leaf produced by the group of the wild-type isolates (Table 4). Analysis of variance did not show significant differences $(P>0.05)$ between the two independent experiments according to the $t$ test (Table 4).

For all isolates, mycelial growth on PDA significantly decreased at an $\mathrm{NaCl}$ concentration of more than $4 \%$ (Table 5). Generally, inhibition due to $\mathrm{NaCl}$ was not significantly different between the two groups of quadruple-resistant and wild-type isolates $(P>0.05)$. As indicated by the negative values of percentage inhibition, 2 to $4 \%$ concentrations of $\mathrm{NaCl}$ stimulated radial growth in vitro in some isolates (Table 5). Analysis of variance did not show significant differences $(P>0.05)$ between the two independent experiments according to the $t$ test (Table 5).

Sequences of the Bos1 gene from procymidone-resistant and -sensitive isolates. The complete Bosl gene was sequenced from the 13 isolates representing five phenotypes. Comparisons of the nucleotide sequence of the Bosl gene from procymidone-sensitive and procymidoneresistant isolates revealed that 13 isolates showed $99 \%$ identities to each other, and all 10 procymidone-resistant isolates had a point mutation of CAG (in sensitive isolates) to $\mathrm{CCG}$ (in resistant isolates) and from AAC (in sensitive isolates) to AGC (in resistant isolates); these mutations caused changes of glutamine (Gln) to proline (Pro) at codon position 369 (Q369P) and asparagine (Asn) to serine (Ser) at codon position 373 (N373S). Other types of point mutations of the Bos 1 gene were not detected from 10 isolates tested.

\section{DISCUSSION}

In this study of $B$. cinerea infecting greenhouse vegetable crops in China, we found many isolates with quadruple resistance to the fungicides pyrimethanil, carbendazim, diethofencarb, and procymidone. To the best of our knowledge, this is the first report of multiply resistant isolates having resistance to pyrimethanil in $B$. cinerea in China. Ten isolates from 10 greenhouses in Shandong Province were all resistant to these four fungicides, and more than $50 \%$ of the isolates from $\mathrm{Ji}$ angsu Province had quadruple resistance. The high level of multiple fungicide resistance found in this study reflects some of the dangers of intensive fungicide use in greenhouse production systems and indicates that fungicide resistance is a serious problem in these regions. Isolates of $B$. cinerea with multiple resistance have also been detected in Spain but only 3\% were resistant to all four fungicides (17). It is unknown why the frequency of quadrupleresistant isolates of $B$. cinerea seems much higher in China than in Spain. One reason could be that the isolates of $B$. cinerea from China were obtained from greenhouse populations exposed to very high fungicide selection pressure.

In the current study, fitness was measured in terms of in vitro mycelial growth, spore production, conidia germination, and osmotic sensitivity to $\mathrm{NaCl}$ and in vivo pathogenicity and spore production. There were no significant differences between the wild-type and the quadruple-resistant groups of isolates in these fitness components. The finding was similar to that of some other studies that measured these variables in $B$. cinerea isolates with resistance to single fungicides $(1,17,22-24)$. To our knowledge, the current study is the first to measure multiple fitness components of quadruple-resistant isolates of $B$. cinerea in China.

In the present study, we obtained a high frequency of isolates resistant to carbendazim and diethofencarb in all three regions, and 10 selected quadruple- resistance isolates exhibited high resistance to both carbendazim and diethofencarb. In contrast, according to Leroux et al. (13), only two benzimidazole-resistant $B$. cinerea phenotypes were detected from French vineyards between 1993 and 1997. The first one had high resistance to carbendazim and, simultaneously, was sensitive to diethofencarb and the second one was moderately resistant to carbendazim and resistant to diethofencarb. In China, we suspect that the high frequency of isolates with resistance to carbendazim and diethofencarb resulted from increased selection pressure because of the repeated use of mixtures of the two fungicides. In three regions studied in this research, $100 \%$ of the isolates were resistant to carbendazim. Moreover, previous studies have demonstrated that carbendazimresistant isolates have fitness characteristics similar to those of the carbendazimsensitive isolates and that resistance to carbendazim was stable $(7,16,26)$. These results suggested that carbendazim should not be used for controlling gray mold in these regions.

Previous studies have indicated that only ungerminated or freshly germinated conidia of $B$. cinerea should be used for in vitro tests for sensitivity of $B$. cinerea isolates to anilinopyrimidines $(3,8,9,14,17)$. Anilinopyrimidines have little effect on germination of $B$. cinerea conidia in vitro but substantially inhibit germ-tube elongation and initial mycelial growth (19). In the present study, we used 17-h-germinated conidia for testing sensitivity of the isolates to pyrimethanil on a synthetic medium. According to a previous study (10), the $\mathrm{EC}_{50}$ for mycelial growth of pyrimethanil-sensitive isolates ranged from 0.09 to $0.44 \mathrm{mg} /$ liter, which was a little

Table 5. $\mathrm{NaCl}$ sensitivity of wild-type isolates of Botrytis cinerea and isolates resistant to carbendazim, procymidone, diethofencarb, and pyrimethanil

\begin{tabular}{lcccc}
\hline & \multicolumn{3}{c}{ Inhibition of mycelial growth (\%) at indicated percent $\mathbf{~ N a C l}^{\mathbf{a}}$} \\
\cline { 2 - 5 } & $\mathbf{2 \%} \mathbf{~ N a C l}$ & $\mathbf{4 \%} \mathbf{~ N a C l}$ & $\mathbf{6 \%} \mathbf{~ N a C l}$ & $\mathbf{8 \% ~} \mathbf{~ N a C l}$ \\
\hline Wild-type isolates & & & & \\
YC4 & -1.4 & 6.1 & 28.7 & 52.0 \\
YC5 & -21.1 & -0.9 & 27.6 & 45.7 \\
YC15 & -12.8 & -9.5 & 22.8 & 44.3 \\
Y71 & -30.5 & -16.1 & 2.3 & 42.7 \\
X9 & -12.4 & -12.5 & 22.5 & 51.8 \\
Quadruple-resistant isolates & & & & \\
07-SD3 & -14.4 & 4.8 & 28.4 & 51.0 \\
08-NJ54 & -13.8 & 5.0 & 30.2 & 53.9 \\
08-NJ59 & -28.6 & -5.2 & 36.3 & 45.6 \\
07-SD5 & -15.3 & 2.2 & 15.6 & 41.1 \\
08-NJ26 & -2.1 & -4.2 & 28.0 & 52.6 \\
08-NJ23 & -7.8 & 2.2 & 25.3 & 49.9 \\
08-NJ30 & -13.0 & -11.2 & 31.7 & 42.7 \\
08-NJ5 & -15.9 & -2.9 & 18.1 & 49.8 \\
08-NJ6 & -16.3 & -8.4 & 33.8 & 55.5 \\
08-HY3 & -24.9 & -15.9 & 27.2 & 52.2 \\
\hline
\end{tabular}

a Values are the mean of two experiments of three replicates each. Analysis of variance did not show significant differences $(P>0.05)$ between the two experiments. Negative values indicate that colony diameters were greater in the presence than in the absence of $\mathrm{NaCl}$. Inhibition due to $\mathrm{NaCl}$ was not significantly different between the group of quadruple-resistant and wild-type isolates $(P>0.05)$ according to $t$ tests. 
higher than that reported in the present study (0.06 to $0.10 \mathrm{mg} / \mathrm{liter})$. The discrepancy in $\mathrm{EC}_{50}$ might result from differences in the inoculum and the assay used in these two studies; in that study (10), agar plugs from the margin of 3-old-day PDA cultures were used as inoculum to test the sensitivity of mycelial growth of $B$. cinerea isolates to pyrimethanil. Studies of $B$. cinerea resistance to anilinopyrimidines have also been carried out in other countries. In a table grape vineyard near Santiago, Chile, Latorre et al. (12) found that $38.5 \%$ of the $B$. cinerea isolates were resistant to anilinopyrimidine fungicides. In Spain, a low frequency $(12 \%)$ of anilinopyrimidineresistant $B$. cinerea isolates was detected in 2000 (17). Also, Myresiotis et al. (18) found a high percentage $(49.1 \%)$ of anilinopyrimidine-resistant isolates on the island of Crete, Greece, during February 2005. In the present study, all 10 of the $B$. cinerea isolates from Shandong Province were resistant to pyrimethanil and more than $50 \%$ of the isolates from Jiangsu Province were resistant to pyrimethanil. All of these results indicated that there is a high risk for the occurrence of anilinopyrimidine resistance in $B$. cinerea. According to Leroux et al. (13), three anilinopyrimidine-resistant phenotypes (AniR1, AniR2, and AniR3) have been identified. AniR1 isolates were resistant only to anilinopyrimidine fungicides and were characterized by high resistance factors, whereas AniR2 and AniR3 types were simultaneously resistant to anilinopyrimidines and fungicides of other classes and were characterized by low resistance factors to anilinopyrimidine fungicides. Our study documented one new anilinopyrimidineresistant phenotype which exhibited high resistance to pyrimethanil and also moderate resistance to procymidone. The resistance factor $\left(\mathrm{EC}_{50}\right.$ of each quadruple isolates to pyrimethanil/mean $\mathrm{EC}_{50}$ of five wild-type isolates to pyrimethanil) ranged from 162 to 330 , which was higher than the resistance factor (9 to 91) for pyrimethanil-resistant isolates previously reported in Spain (17) and the resistance factor (20 to 125) for AniR1 isolates in French vineyards (13).

In conclusion, fungicide resistance is a serious problem in Shandong and Jiangsu Provinces of China. Growers can no longer rely on benzimidazole, $N$-phenylcarbamate, and dicarboximide fungicides as primary management tools because the current strategy of mixtures and alterna- tions is not working and multiple resistance is developing. Other disease management strategies should be employed to control this severe disease. Control of gray mold should focus on integrated disease management, including the use of new, low-risk fungicides with different modes of action. China now is facing a challenge to find alternative fungicides for control of gray mold caused by $B$. cinerea.

\section{ACKNOWLEDGMENTS}

This study was sponsored by the State "973" programs from the Ministry of Science and Technology of China (no. 2006CB101907 and 2009CB118906), the State "863" programs from the Ministry of Science and Technology of China (no. 2006AA10A211 and 2008AA10Z414), and the National Natural Science Foundation of China (no. 30671048 and 30671384)

\section{LITERATURE CITED}

1. Bardas, G. A., Myresiotis, C. K., and Karaoglanidis, G. S. 2008. Stability and fitness of anilinopyrimidine-resistant strains of Botrytis cinerea. Plant Pathol. 98:443-450.

2. Baroffio, C. A., Siegfried, W., and Hilber, U. W. 2003. Long-term monitoring for resistance of Botryotinia fuckeliana to anilinopyrimidine, phenylpyrrole, and hydroxyanilide fungicides in Switzerland. Plant Dis. 87: 662-666.

3. Birchmore, R. J., and Forster, B. 1996. FRAC methods for monitoring the sensitivity of $\mathrm{Bo}$ trytis cinerea to anilinopyrimidine fungicides. Bull. OEPP/EPPO Bull. 26:181-197.

4. Brown, J. W. 1999. The ribonuclease P database. Nucleic Acids Res. 27:314-314.

5. Ding, Z., Liu, F., Wang, H. L., Wu, C.X., and M, L. Y. 2001. Studies on the multiple fungicide resistance to Botrytis cinerea J. Shandong Agric. Univ. 32:452-456.

6. Elad, Y., Yunis, H., and Katan, T. 1992. Multiple fungicide resistance to benzimidazoles, dicarboximides and diethofencarb in field isolates of Botrytis cinerea in Israe1. Plant Pathol. 41:41-46.

7. Faretra, F., Pollastro, S., and Di Tonno, A. P. 1989. New natural variations of Botrytis cinerea coupling benzimidazole-resistant to insensitivity toward the $\mathrm{N}$-phenylcartamate diethofencarb. Phytopathol. Mediterr. 28:98-104

8. Hiber, U. W., and Hiber-Bodmer, M. 1998. Genetic basis and monitoring of resistance of Botryotinia fuckeliana to anilinopyrimidines. Plant Dis. 82:496-500.

9. Hiber, U. W., and Schüepp, H. 1996. A reliable method for testing the sensitivity of Botryotinia fuckeliana to anilinopyrimidines in vitro. Pestic. Sci. 47:241-247.

10. Ji, M. S., Qi, Z. Q., Wang, Y. Z., Cheng, G. W., and $\mathrm{Zu}, \mathrm{M}$. 2003. Resistance of Botrytis cine$r e a$ to pyrimethanil in tomato. Acta Phytophylacica Sin. 3:396-400.

11. Katan, T., Elad, Y., and Yunis, H. 1989. Resistance to diethofencarb (NPC) in benomylresistant field isolates of Botrytis cinerea. Plant Pathol. 38:86-92.

12. Latorre, B. A., Spadaro, I., and Rioja, M. E. 2002. Occurrence of resistance strains of Botrytis cinerea to anilinopyrimidine fungicides in ta- ble grapes in Chile. Crop Prot. 21:957-961.

13. Leroux, P., Chapeland, F., Desbrosses, D., and Gredt, M. 1999. Patterns of cross-resistance to fungicides in Botryotinia fuckeliana (Botrytis cinerea) isolates from French vineyards. Crop Prot. 18:687-697.

14. Leroux, P., and Gredt, M. 1996. In vitro methods for monitoring pyrimethanil resistance of Botrytis cinerea in grapevine. Bull. OEPP/EPPO Bull. 26:186-188.

15. Ma, Z., Yan, L.Y., Luo, Y., and Michailides, T. J. 2007. Sequence variation in the twocomponent histidine kinase gene of Botrytis cinerea associated with resistance to dicarboximide fungicides. Pestic. Biochem. Physiol. 88:300-306

16. Moorman, G. W., and Lease, R. J. 1992. Benzimidazole-and dicarboximideresistant Botrytis cinerea from Pennsylvania greenhouses. Plant Dis. 76:477-480.

17. Moyano, C., Gómez, V., and Melgarejo, P. 2004. Resistance to pyrimethanil and other fungicides in Botrytis cinerea populations collected on vegetable crops in Spain. J. Phytopathol. 152:484-490.

18. Myresiotis, C. K., Karaoglanidia, G. S., and Tzavella-Klonari, K. 2007. Resistance of Botrytis cinerea isolates from vegetable crops to anilinopyrimidine, phenylpyrrole, hydroxyanilide, benzimidazole, and dicarboximide fungicides. Plant Dis. 91:407-413.

19. Newman, G. L., Winter, E. H., and Pittis, J. E. 1992. Pyrimethanil: a new fungicide. Bright Crop Prot. Conf. Pests Dis. 1:395-404.

20. Oshima, M., Banno, S., Okada, K., Takeuchi, T., Kimura, M., Ichiishi, A., Yamaguchi, I., and Fujimura, M. 2006. Survey of mutations of a histidine kinase gene $B c O S 1$ in dicarboximideresistant field isolates of Botrytis cinerea. J. Gen. Plant Pathol. 72:65-73

21. Pappas, A. C. 1997. Evolution of fungicide resistance in Botrytis cinerea in protected crops in Greece. Crop Prot. 16:257-263.

22. Raposo, R., Delcan, J., Gomez, V., Melgarejo, P. 1996. Distribution and fitness of isolates of Botrytis cinerea with multiple fungicide resistance in Spanish greenhouses. Plant Pathol. 45:497-505.

23. Raposo, R., Gomez, V., Urrutia, T., and Melgarejo, P. 2000 Fitness of Botrytis cinerea associated with dicarboximide resistance. Phytopathology 90:1246-1249.

24. Raposo, R., Gomez, V., Urrutia, T., and Melgarejo, P. 2001. Survival of Botrytis cinerea in southeastern Spanish greenhouses. Eur. J. Plant Pathol. 107:229-236.

25. Yarden, O., and Katan, T. 1993. Mutations leading to substitutions at amino acids 198 and 200 of beta-tubulin that correlated with benomyl-resistance phenotypes of field strains of Botrytis cinerea. Phytopathology 83:14781483.

26. Yourman, L. F., Jeffers, S. N., and Dean, R. A. 2001. Phenotype instability in Botrytis cinerea in the absence of benzimidazole and dicarboximide fungicides. Phytopathology 91:307-315.

27. Zhu, G. N., Huang, F. X., and Cai, J. H. 2003. Multiple Fungicide-resistance of Tomato Botrytis cinerea in Guangxi. China Veg. 4:14-16.

28. Zhu, H., Qu, F., and Zhu, L. H. 1994. Isolation of genomic DNAs from fungi using benzyl chloride. Mycosystema 13:34-40. 